\title{
A novel liquid bridge model for estimating SWCC and permeability of granular material
}

\author{
Xiaoliang Wang ${ }^{1}$, Jiachun $\mathrm{Li}^{*}$ \\ Key Laboratory for Mechanics in Fluid Solid Coupling Systems, Institute of Mechanics, Chinese Academy of Sciences, Beijing, China
}

\section{A R T I C L E I N F O}

\section{Article history:}

Received 1 June 2014

Received in revised form 15 October 2014

Accepted 20 January 2015

Available online 28 January 2015

\section{Keywords:}

Unsaturated granular materials

Discrete element method

Soil water characteristic curves

Liquid bridge

\begin{abstract}
A B S T R A C T
As traditional liquid bridge model based on Yang-Laplace theory fails to model behaviors of unsaturated granular materials when liquid bridges fuse with each other in funicular and capillary regimes, a method called "Redistribution of Air Volume and Reduction of Liquid Bridge Force" is proposed, and incorporated into the original discrete element method to resolve this issue. Both soil water characteristic curve and suction stress characteristic curve are worked out by the modified discrete element method, the results of which coincide with theoretical solutions for simple cubic packing and tetrahedral packing of granular materials. Furthermore, parameter study shows that soil water characteristic curve depends on effective particle diameter, particle size distribution and packing density. Typical soil water characteristic curves of sand and silt are obtained using the modified method, with a trend similar to that of experiment qualitatively. With the help of Mualem model and Kozeny-Carman equation, permeability is also predicated for granular materials. In particular, the air entry value coincides with or close to those of typical sand and silt in magnitude. Finally, a case study of SWCC prediction for sandy soil is implemented with acceptable results. We may conclude that the modified discrete element method is capable of predicting hydraulic properties of granular materials qualitatively and semi-quantitatively.
\end{abstract}

(C) 2015 Published by Elsevier B.V.

\section{Introduction}

There is vast expanse of arid and semi-arid areas on the earth surface where soil is mostly in an unsaturated state. Hence, people need to explore seepage flow in unsaturated soil for economy related to agriculture, forestry and husbandry. On the other hand, it is indispensable to have an in-depth understanding of terrestrial process for climate study, in which water and heat exchanges between land and atmosphere are remarkably important [1]. In particular, when the strategic plan of natural and human induced disasters was put on the agenda of International Council of Scientific Unions (ICSU), people have paid more attention to extreme hydro-meteorological hazards such as landslides and debris flows [2]. In order to reduce the risk in this regard, it is necessary for us to explore their mechanism by following the transient seepage process from unsaturated to saturated states in disaster evolution. During heavy rainfall, infiltration and runoff take place over a slope and the saturated zone gradually expands with a wet front moving downwards [3,4]. Fu and Li have also noticed that the strength degradation or softening of soil with the degree of saturation plays a decisive role to initiate landslides, and they have proposed three water-

\footnotetext{
* Corresponding author at: Institute of Mechanics, Chinese Academy of Sciences, No. 15 Beisihuanxi Road, Beijing 100190, China. Tel.: + 8682544201.

E-mail addresses: wangxiaoliang52086@126.com (X. Wang), jcli05@imech.ac.cn (J. Li).

1 Address: Institute of Mechanics, Chinese Academy of Sciences, No. 15 Beisihuanxi Road, Beijing 100190, China.
}

induced softening models [5]. Therefore, poor understanding in both mechanical and hydraulic behaviors of unsaturated granular materials motivated us to study this topic by discrete element method (DEM) based on micromechanics in this paper.

For unsaturated soil, we know that the soil matric suction may consist of matric or solute potentials etc. [6]. Soil water characteristic curve (SWCC) describing the relationship between suction and water content provides constitutive relationship, major parameters such as specific water capacity, relative permeability [7] and so on, are of great importance for unsaturated seepage. At the same time, SWCC plays a significant role in constitutive modeling of wet granular materials, which couple the hydraulic and mechanical behaviors, such as Li [8], Sheng [9] and Gens [10]. SWCC is usually obtained via numerical fitting of experimental data of soil moisture and suction tests by mathematical models, such as the Brooks and Corey (BC) model [11], van Genuchten (VG) model [12], and Fredlund and Xing (FX) model [13]. Although prediction of SWCC by using particle size distribution and capillary water state has progressed a lot [14-16], deep mechanism and coupling of capillary water and particles still need to be studied. Because the experimental measurements of permeability for unsaturated granular materials are hard and time consuming, permeability can also be easily worked out by integration of SWCC based on statistical methods including the Mualem model [17] and Burdine model [18].

Recently, DEM developed in 1979 by Cundall [19], has been extended to investigate behavior of unsaturated granular materials. Mechanical interaction between particles such as normal, shear and rolling 
interaction [20-23] has matured and already been incorporated into a few open source DEM code such as Yade [24]. In contrast, the work on physical-chemical interaction between particles is relatively fewer and only the works of Anandarajah [25,26] and jiang [27] are representative. Furthermore, the study on influence of water content on physical-chemical process is especially lacking. Richefeu $[28,29]$, Shamy [30] and Soulié [31] allowed liquid bridges to form in between separated but closing particles and calculated liquid bridge force by approximate formulae. Jiang [32] assumed that meniscus occurs in contacting particles then with liquid bridge force calculated explicitly by analytical formulae. Scholtès [33-35] worked out ten files recording both liquid bridge force and meniscus volume in dimensionless form and thus facilitate the calculation of liquid bridge force by interpolation. Liquid bridge model based on Yang-Laplace theory has been applied to investigate behavior of unsaturated granular materials. For instance, Richefeu [28] and Scholtès [33] studied the cohesion of three dimensional disperse granular materials in this way and found that cohesion increases with water content in pendular state. Scholtès [34] also produced SWCC in pendular state and analyzed hysteresis by ink-bottle mechanism.

All aforementioned scientists only restricted their research in the pendular state of unsaturated granular materials. Almost there is no research available to consider the interaction force and liquid volume of unsaturated soil in funicular and capillary regimes in the framework of DEM-liquid bridge coupling model. As an exception, only Jiang [32] preliminarily touched on the issue when he was concerned with effective stress of unsaturated granular materials.

A method called "Redistribution of Air Volume and Reduction of Liquid Bridge Force" is proposed based on the work of Jiang [32] in this study to extend the original liquid bridge model by the YoungLaplace theory in DEM to funicular and capillary regimes. Section 2 describes DEM and "Redistribution of Air Volume and Reduction of Liquid Bridge Force" approach in detail. The verification of this new approach is implemented in Section 3 for simple cubic packing and tetrahedral packing. Section 4 further addresses the influences of particle size distribution, packing density, effective diameter and confining stress on SWCC and permeability by numerical simulation based on this modified DEM. A case study for the sandy soil is implemented in Section 5. Finally, we come to a few very useful conclusions.

\section{DEM and modified DEM}

Since the invention of DEM by Cundall and Strack [19], DEM has been widely applied to study fundamental behavior of both soil and rock, such as dilatancy of granular materials [23,36,37], behavior of rock and rock joint under uniaxial and triaxial compression etc. [38,39]. With inter-particle capillary force taken into account, DEM has been extended to examine the behavior of unsaturated granular materials including SWCC [32] and strength under bi/triaxial compression tests $[32,33]$ in recent years. For instance, liquid bridge model based on Yang-Laplace theory has been broadly used and implemented in Yade [40]. However, the work of Scholtès [33-35] is only applicable in pendular regime, while the 2D approach of Jiang [32] is suitable for cases when liquid bridges exist between contacting particles. The method fails to model 3D granular material phenomena in funicular and capillary regimes due to the complicated water distribution in the packing.

Based on the works of both Jiang [32] and Scholtès [35], the "Redistribution of Air Volume and Reduction of Liquid Bridge Force" approach is proposed and implemented on the platform of the open source Yade [41].

\subsection{Contact model}

The interaction between two contacting particles is decomposed into a normal component $F_{n}$ and a shear component $F_{s}$, where the normal part is modeled by a spring with stiffness $k_{n}$, and the shear part is modeled by a shear spring with stiffness $k_{s}$. The definitions of $k_{n}$ and $k_{s}$ are shown in Eqs. (1) and (2), in which $E$ is contact modulus of particles, $R_{1}$ and $R_{2}$ are diameters of the two contacting particles, respectively. The objective of doing so is to keep macroscopic the Young's modulus of granular packing proportional to the contact modulus [33]. A Mohr-Coulomb friction is added into the shear part to simulate the frictional behavior as shown in Eq. (3), where $\mu$ and $\phi$ are friction coefficient and inter-particle friction angle, respectively. If not specially stated in the following passage, contact modulus $E$ is assumed as $50 \mathrm{MPa}, \alpha$ as 0.4 and $\phi$ as a number of values until $30^{\circ}$ corresponding to different initial porosities.

$k_{n}=2 \cdot \frac{E \cdot R_{1} \cdot R_{2}}{\left(R_{1}+R_{2}\right)}$

$k_{t}=\alpha \cdot k_{n}$

$\mu=\tan (\phi)$

\subsection{Calculation of liquid bridge force and volume}

Water inside the pores of granular materials exhibits some kinds of morphologies, namely, pendular, funicular and capillary states. In the pendular regime when water saturation degree is as low as $15 \%$, water exhibits a clear pattern and liquid bridges may occur in between independent particles. It is obvious that the surface of a liquid bridge can be formed by revolving an arc tangent to two spherical particles, as shown in Fig. 1. Based on Yang-Laplace theory, the relationship between suction $\mathrm{Su}$ and principal curvature radius $r_{1}$ and $r_{2}$ can be written in Eq. (4), where $\sigma$ is the surface tension.

$S u=\sigma\left(\frac{1}{r_{2}}-\frac{1}{r_{1}}\right)$

If the liquid bridge force pulling the two particles towards each other is represented by $F^{c a p}$ [35], then $F^{c a p}$ and the bridge volume can be calculated via iteration of Eq. (4). All the work has been completed by Scholtès [33,35] and incorporated into Yade.

\section{3. "Redistribution of air volume and reduction of liquid bridge force" approach}

The above theory and numerical implementation have already been applied to investigate behavior of unsaturated granular materials including SWCC and triaxial compression behavior only in the pendular state. As water content is increasing, however, a liquid bridge is very possible getting closer to its neighboring bridges and then fusion of them may occur, as shown in Fig. 2. In particular, the pore space between them can soon be flooded by water when bridges become unstable. Then the granular material is in the funicular regime, in which slight reduction of pore pressure can result in apparent rise in water content. As water content continues to grow, wet granular material will be in its capillary regime, which is already very close to saturated regime and the granular materials are usually regarded as saturated soil.

If liquid bridge fusion happens, new physical theory and numerical algorithm for the calculation of force and water volume between particles should be developed. Nevertheless, there is no straightforward method available for capillary force and water volume in this regime thus far owing to the complicated reticulate morphologies of water in pores [2]. For this reason, a new approach as a simplification of the above fusion process is proposed. Liquid bridge model based on Yang- 


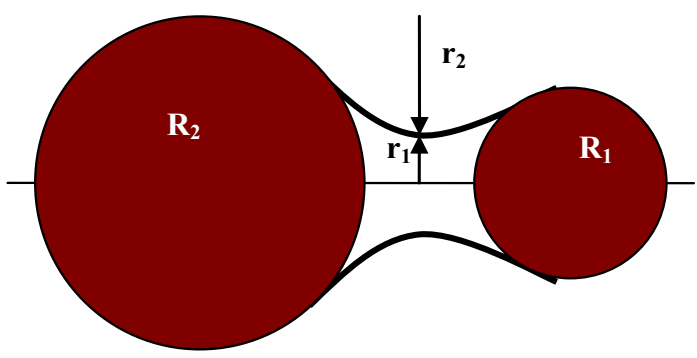

Fig. 1. Morphology of liquid bridge in between two particles.

Laplace theory with a modification is still kept valid in the expressions of the liquid bridge force and volume, as shown in Eqs. (5) and (6).

$V_{a}^{i}=\left(V_{V}-\sum_{j} V_{m}^{j}\right) \cdot \frac{m_{i}}{M a x M e}$

$F^{c a p^{\prime}}=F^{c a p} \cdot \frac{1}{\left(1+m_{i}\right)}$

where $V_{a}^{i}$ is water volume added to the $i$ th liquid bridge when fusion happens, $V_{V}$ is the total volume of pore, $V_{m}^{j}$ is the volume of the $j$ th liquid bridge based on Yang-Laplace theory, $m_{i}$ is the fusion number of the $i$ th bridge, which is the number of bridges contacting or overlapped with the $i$ th bridge. For example as shown in Fig. 2, bridge 1 overlaps with the 2 nd to 5 th bridges, so the fusion number $m_{i}$ of bridge 1 is 4 . MaxMe is the average maximum fusion number, very close to the average fusion number of a bridge in saturated regime. A lot of numerical studies indicate that, MaxMe approaches the number in the saturated regime as shown in Fig. 3, which is the evolution of average fusion number in the third parameter regime. Liquid bridge force is calculated via a linear reduction method with the fusion number. When no fusion takes places in the pendular regime with $m_{i}$ being zero, the modification method recovers the results of Yang-Laplace theory in pendular regime as stated before.

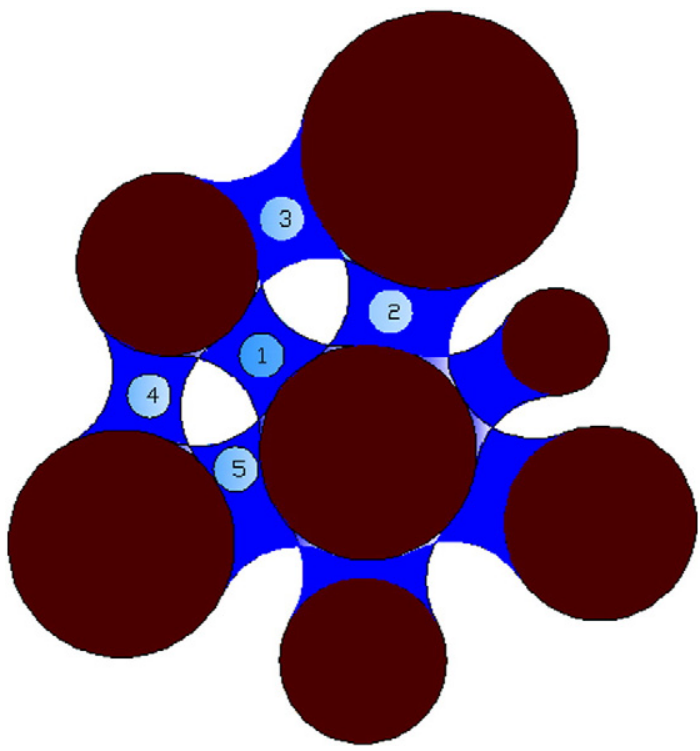

Fig. 2. Morphologies of liquid bridges in funicular regime of granular materials. Circles are solid particles, and the blue meniscus is liquid bridge, and the white space is occupied by air

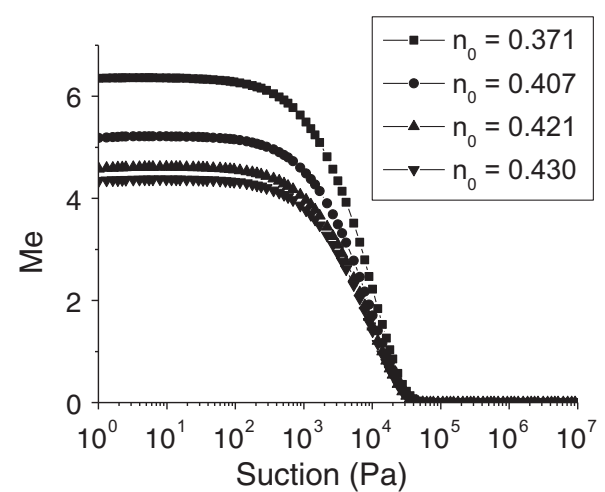

Fig. 3. Evolution of fusion number with suction under different initial porosities, here $M e$ is the average fusion number of a bridge, and $n_{0}$ is the porosity.

As for simple cubic packing granular material, MaxMe is 8 for each bridge. The addition of pore water volume using Eq. (5) is accurate for simple cubic packing, in which due to the symmetry, fusion number could be only 0 for pendular regime, and 8 for funicular and capillary regime. The reduction of liquid bridge force using Eq. (6) is approximate for simple cubic packing, due to the symmetry, when fusion happens, all liquid bridge forces should be reduced to 0 . It is why some authors set liquid bridge force to 0 , if the fusion number is larger than one or two, such as Jiang [32]. But for polydisperse random granular packing, the addition of pore water volume and reduction of liquid bridge force is approximate, which will be validated through the predication of SWCC for typical sand and silt in the next passage.

\section{Verification of the modified DEM}

\subsection{Analytical solution of simple cubic packing}

Simple cubic packing and tetrahedral packing are the simplest structures in three dimensional space. We find that SWCC and the strength of unsaturated soil for this structure can be derived theoretically. Geometry illustration of two contacting particles of same size and the liquid bridge is shown in Fig. 4. The packing structures of simple cubic packing and tetrahedral packing are illustrated in Fig. 5.

It is assumed that the surface of the bridge is a revolution surface of an arc tangent to the two particles, the two principal curvature of the bridge surface is $r_{1}$ and $r_{2}$, the filling angle $\theta$ and the radius of the particle $r$.

The relationship between soil matric suction and the principal curvature radius obeys Young-Laplace theory as Eq. (4) represents.

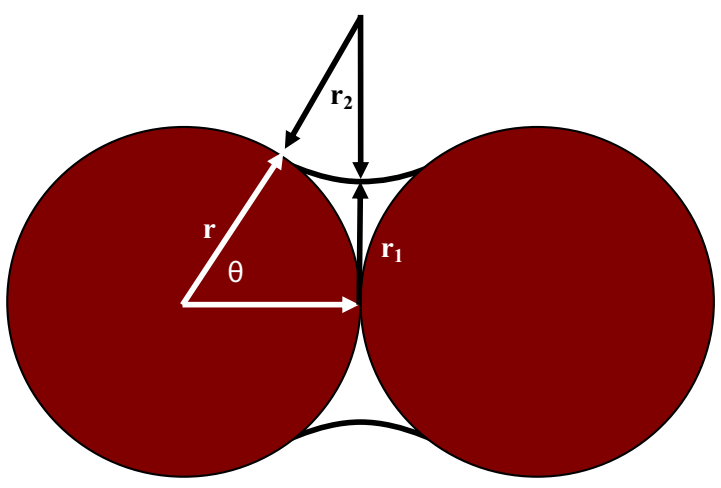

Fig. 4. Illustration of liquid bridge formed in between two contacting particles of the same size. 


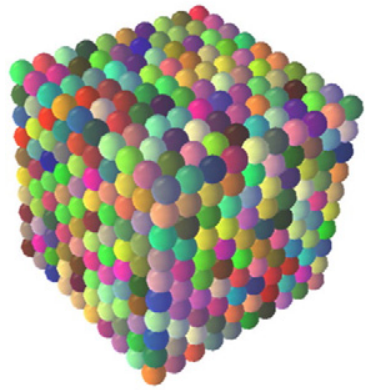

(a)

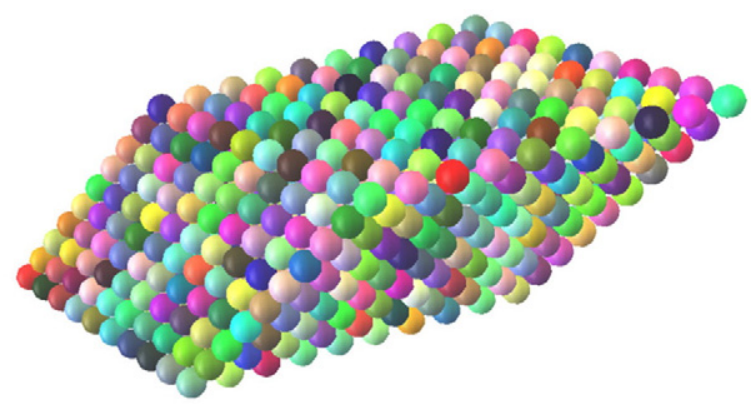

(b)

Fig. 5. Simple cubic granular packing (a) and tetrahedral packing (b).

From geometric relations, $r_{1}$ and $r_{2}$ can be figured out via Eqs. (7) and (8).

$r_{2}=r(\sec \theta-1)$

$r_{1}=r(\tan \theta-\sec \theta+1)$

Substituting Eqs. (7) and (8) into Eq. (4), the relations between filling angle and suction are obtained, as shown in Eq. (9).

$S u=\frac{\sigma}{r}\left[\frac{1}{(\sec \theta-1)}-\frac{1}{(\tan \theta-\sec \theta+1)}\right]$

which can be further simplified to Eq. (10).

$2\left(1+\frac{r S u}{\sigma}\right) \tan ^{2} \frac{\theta}{2}+\tan \frac{\theta}{2}-1=0$

Then, theoretical solution of filling angle is obtained in Eq. (11).

$\tan \frac{\theta}{2}=\frac{-1+\sqrt{\Delta}}{2 a}$

where $a=2\left(1+\frac{r S u}{\sigma}\right), \Delta=9+8 \frac{r S u}{\sigma}$.
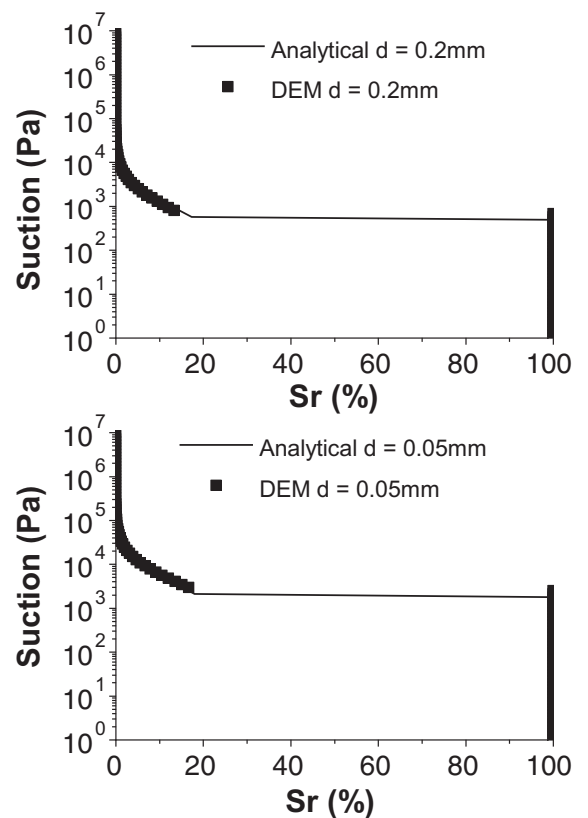

For simple cubic granular packing, the degree of saturation $\mathrm{Sr}$ and the tension stress or suction stress $\sigma_{s}$ according to Lu $[42,43]$, are derived as shown in Eqs. (12) and (13).

$S r=\frac{3 \pi(\sec \theta-1)^{2}\left[1-\left(\frac{\pi}{2}-\theta\right) \tan \theta\right]}{2\left(2-\frac{\pi}{3}\right)}$

$\sigma_{s}=\frac{\pi}{4}(\tan \theta-\sec \theta+1)^{2} \frac{\tan \theta}{(\tan \theta-2 \sec \theta+2)} S u$

The value of $\theta$ is the filled angle as shown in Eq. (11). When $\theta$ is less than $45^{\circ}$, Eqs. (12) and (13) work. On the other hand, when $\theta$ is larger than $45^{\circ}$, all the liquid bridges fuse with all pores being flooded with water which causes the degree of saturation rise to $100 \%$ and the suction stress vanishes.

As for tetrahedral granular packing, the degree of saturation $\mathrm{Sr}$ and the tension stress or suction stress $\sigma_{s}$, are derived as shown in Eqs. (14) and (15).

$S r=\frac{180}{7}(\sec \theta-1)^{2}\left[1-\left(\frac{\pi}{2}-\theta\right) \tan \theta\right]$

Fig. 6. DEM solutions and theoretical solutions of SWCCs of the four simple cubic packing with different diameters. 

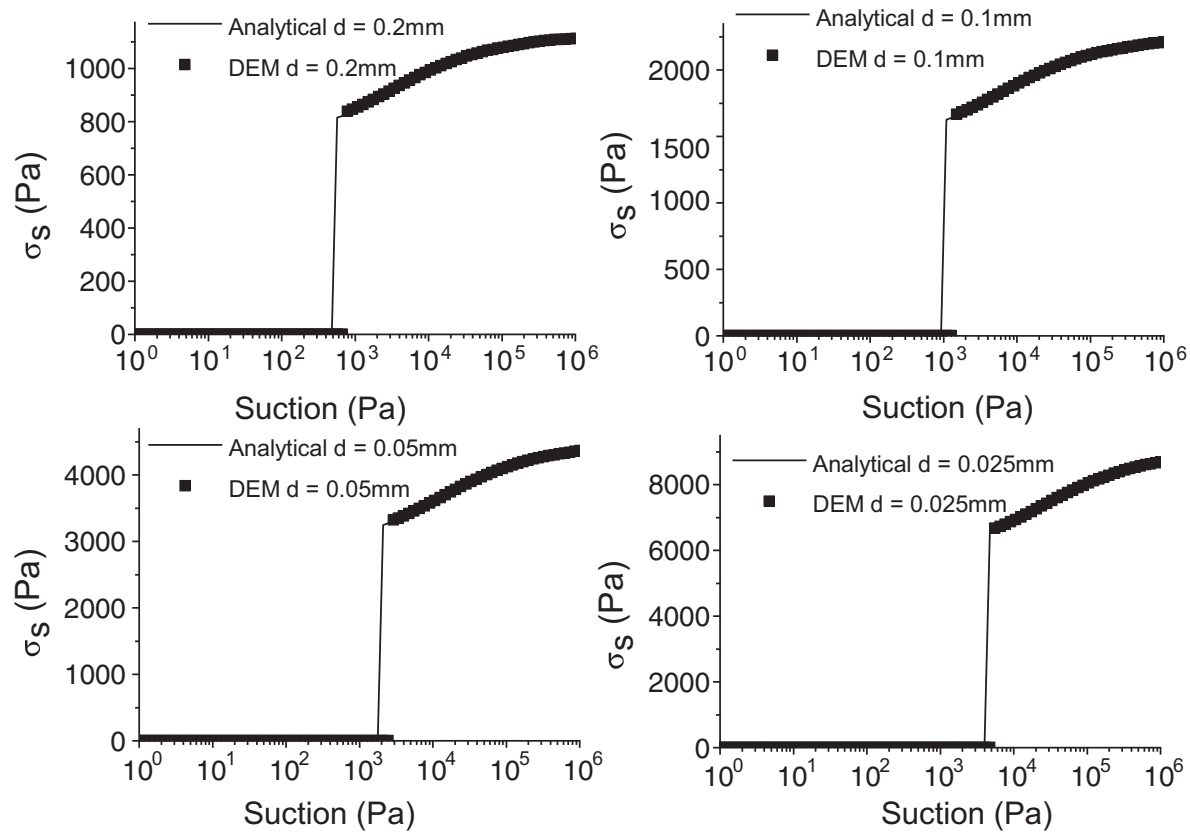

Fig. 7. DEM solutions and theoretical solutions of SSCCs of the four simple cubic packing with different diameters.

$\sigma_{s}=\frac{20}{9}(\tan \theta-\sec \theta+1)^{2} \frac{\tan \theta}{(\tan \theta-2 \sec \theta+2)} S u$

The critical filled angle is $30^{\circ}$ for tetrahedral packing granular material.

\subsection{DEM simulation results}

Four cases of both simple cubic packing and tetrahedral packing samples with different particle sizes were generated as shown in Fig. 5. Particle diameters are $0.2 \mathrm{~mm}, 0.1 \mathrm{~mm}, 0.05 \mathrm{~mm}$ and $0.025 \mathrm{~mm}$, respectively. After the sample is generated, a suction control test is conducted, and water content, saturation degree, suction stress etc. were monitored. In order to make the granular structure the same as that of simple cubic packing and tetrahedral packing in the whole testing process, the motion of all particles are fixed for the validation cases. SWCCs and suction stress characteristic curves (SSCC) of simple cubic packing are plotted in Figs. 6 and 7, and those of tetrahedral packing is shown in Figs. 8 and 9.

From Figs. 6 and 8, SWCC by the modified DEM agrees well with the theoretical solution. Degree of saturation rises to $100 \%$ at filled angle $45^{\circ}$ for simple cubic packing and $30^{\circ}$ for tetrahedral packing, because all the
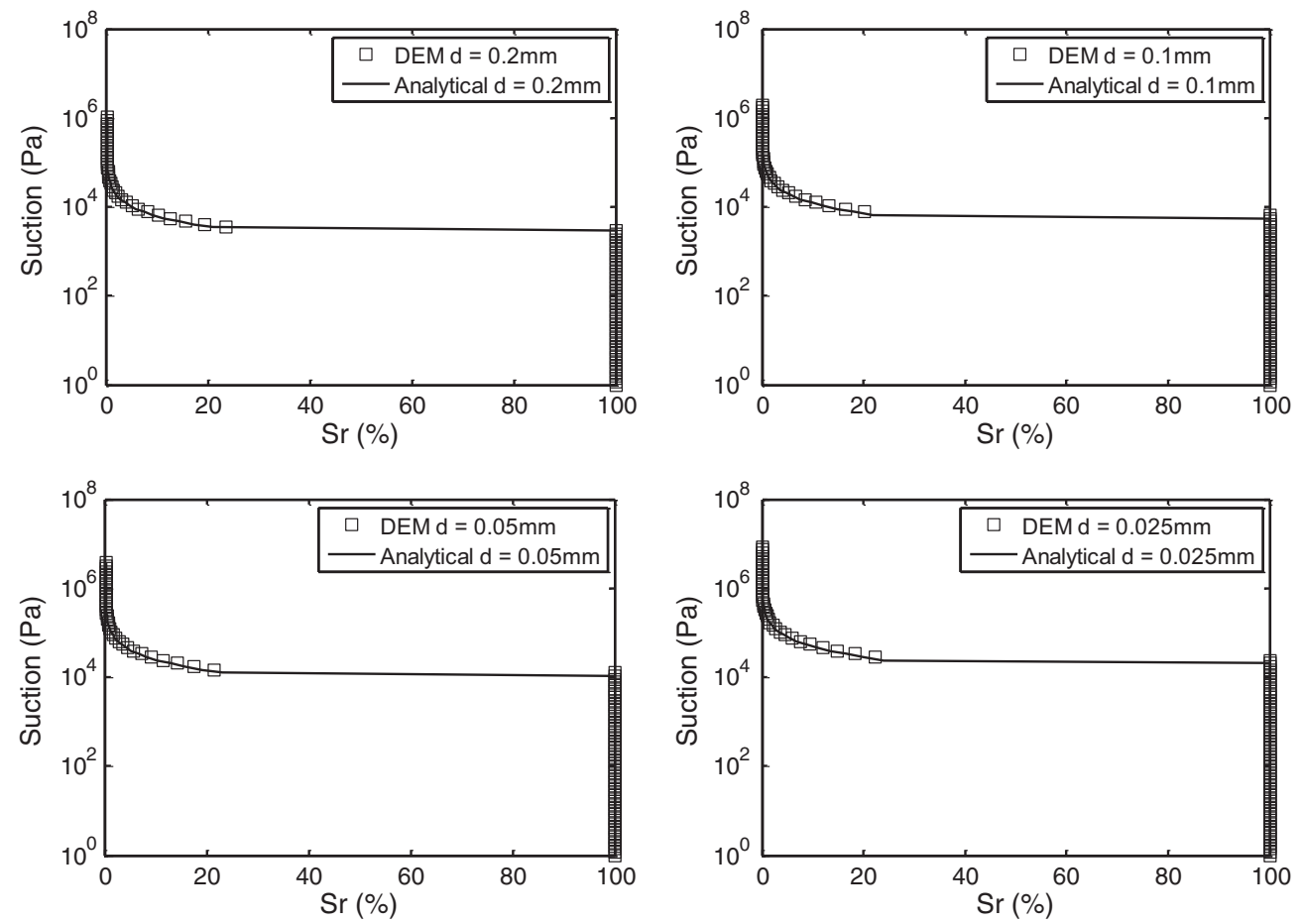

Fig. 8. DEM solutions and theoretical solutions of SWCCs of tetrahedral packing with different diameters. 

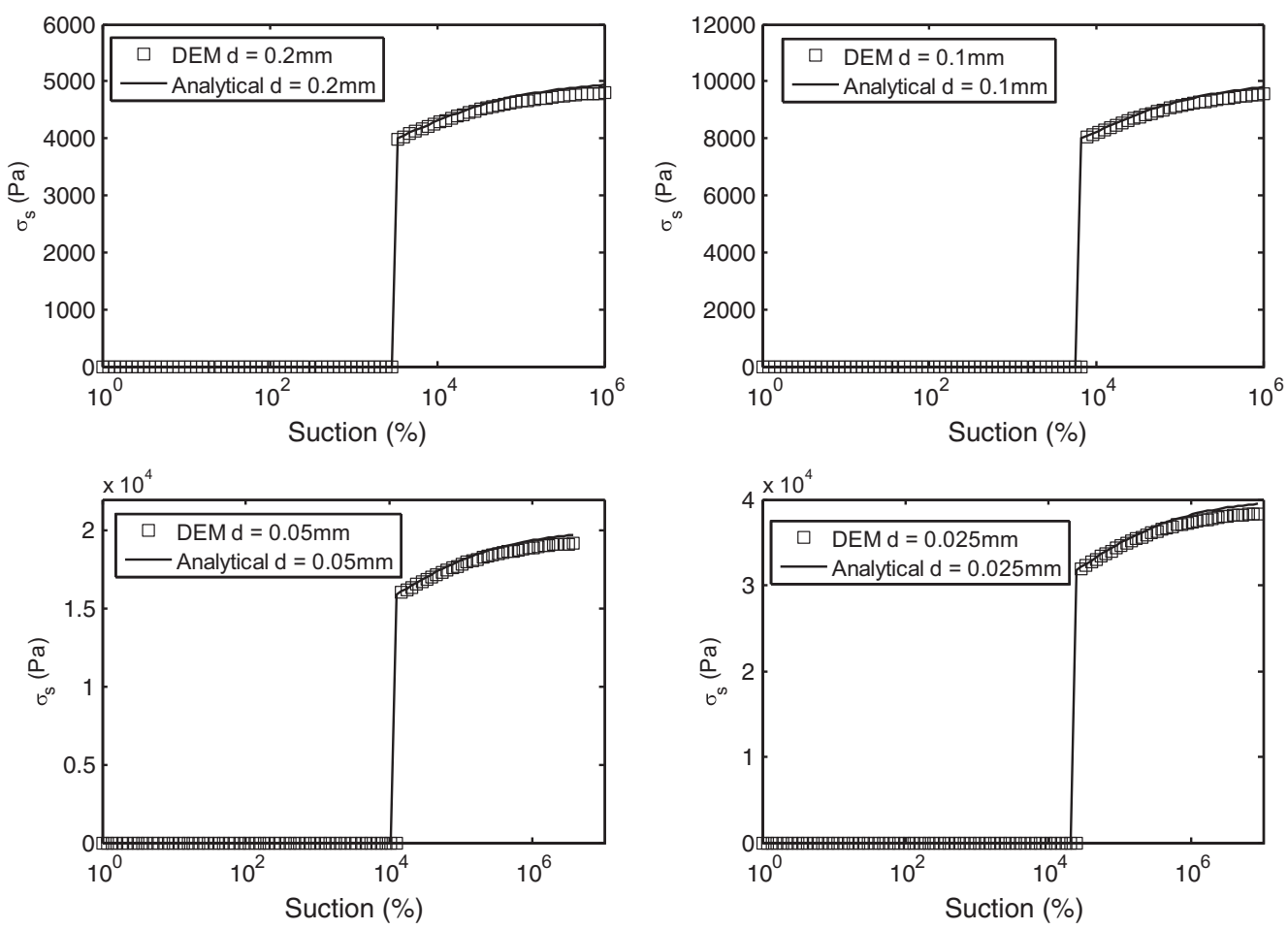

Fig. 9. DEM solutions and theoretical solutions of SSCCs of tetrahedral packing with different diameters.

pores are flooded with water all of a sudden. The degrees of saturation are about $17 \%$ for simple cubic packing and $23 \%$ for tetrahedral packing. The study of Jiang [32] showed the same situation in 2D case for simple cubic packing.

From Figs. 7 and 9, SSCC by the modified DEM also coincides with the theoretical solution. As soon as the filling angle reaches $45^{\circ}$ for simple cubic packing and $30^{\circ}$ for tetrahedral packing, the suction stress immediately vanishes because all the pores are filled with water. Validated theoretically and experimentally for various types of soil [44,45], SSCC is proposed by Lu [43] and applied in the calculation of safety factor for slope under rainfall [46]. In contrast, SSCC is derived via a micromechanical method in this study.

\section{Parameters influences study}

SWCC describing relationship between water content and soil matric suction is affected by several factors, such as particle size distribution, grain size and soil structure etc. [6]. Based on the modified DEM, four influential factors including particle size distribution (PSD), packing density, effective grain diameter, and confining stress are analyzed.

\subsection{Influence of PSD}

Normalized incomplete Beta function [47] was used to generate four cases with different PSDs, as shown in Fig. 10, where PSD 2 and PSD 3 are well graded, while PSD 1 and PSD 4 are uniform. In a box of $1 \mathrm{~mm} \times 1 \mathrm{~mm} \times 1 \mathrm{~mm}, 10,000$ particles were generated. Then a radius expansion method is used to simulate the consolidation process to maintain a confining stress of $10 \mathrm{kPa}$, in which inter-particle friction angle is set as $0.5^{\circ}$ to keep the sample dense. Then, suction controlled tests were performed over the sample with water content monitored. As shown in Fig. 11, compared to the sharp change of SWCC of simple cubic packing, polydisperse size and random arrangement render the SWCC to vary smoothly from pendular to funicular and capillary regimes.
In geotechnical circle, the models of Brooks-Corey (BC) [11], van Genuchten (VG) [12] and Fredlund-Xing (FX) [13] are usually used for SWCC numerical fitting by many scientists and engineers. The VG model is used here to fit SWCC data given by the modified DEM. The mathematical formula of VG model is shown in Eq. (14).

$\Theta=\left[\frac{1}{1+(\alpha \psi)^{n}}\right]^{\left(1-\frac{1}{n}\right)}$

where $\Theta$ is the effective degree of saturation, and $\psi$ is matric suction, $\alpha$ and $n$ are fitting parameters, $\alpha$ is close to the inverse of air entry value, $n$ represents the influence of the distribution of pores on the macroscopic degree of smooth of SWCC. A smaller $n$ produces a smoother

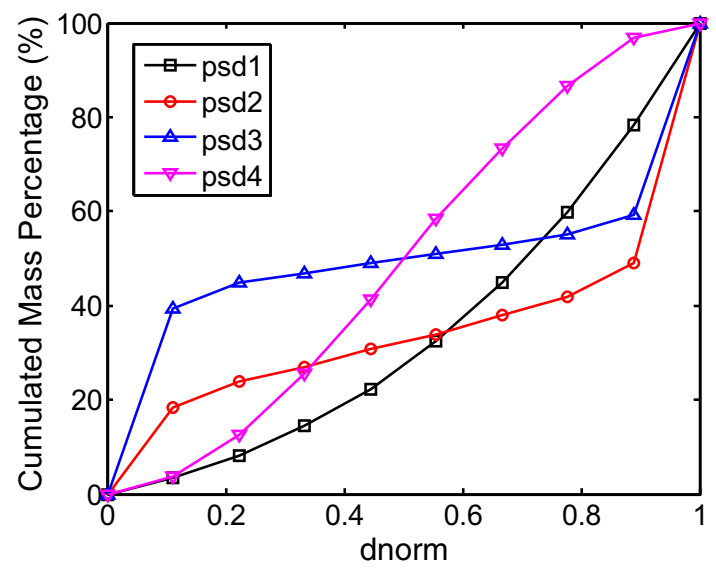

Fig. 10. PSDs of the four different cases in normalized form, here $d_{50}$ which corresponds to the sieve sizes that $50 \%$ of the particles by weight pass through of the four samples are $0.06 \mathrm{~mm}, 0.2 \mathrm{~mm}, 0.1 \mathrm{~mm}$ and $0.07 \mathrm{~mm}$, respectively, and the coefficients of uniformity $\mathrm{Cu}\left(d_{60} / d_{10}\right)$ are $1.4,5.2,6.0$ and 2.1 , respectively, and $d$ norm $=(d \max -d)$ $(d \max -d \min )$, where $d \max , d$ and $d$ min denote diameter of largest, current and minimum particles. 


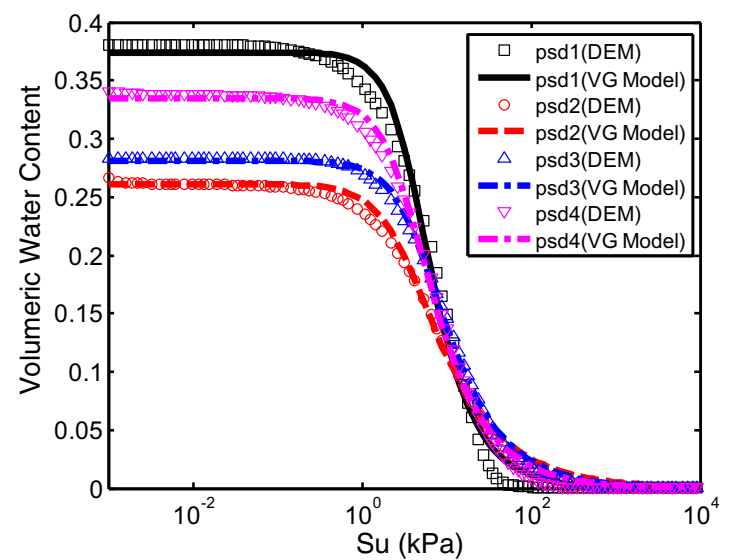

Fig. 11. SWCC of the four cases made of different PSDs and their fitting results by VG model.

transition of SWCC from pendular to funicular and capillary regimes. VG model [12] is chosen for SWCC, and Mualem model [14] is chosen for permeability to fit the data on the platform of RETC code [48]. The permeability of the saturated granular material is estimated by the standard Kozeny-Carman equation as shown in Eq. (15).

$k=\frac{\gamma}{\mu} \frac{1}{K_{0} T^{2} S_{0}^{2}}\left(\frac{e^{3}}{1+e}\right)$

where $k$ is the saturated permeability, $\gamma$ and $\mu$ are the unit weight and dynamic viscosity of water, respectively. $K_{0}$ represents the pore shape factor, and $T$ corresponds to the turtuosity effects, which are estimated as 2.5 and 1.414 here for the narrow graded soil [6]. $S_{0}$ is the wetted surface area per unit volume of particles, which can be computed from the particle size distribution according to Chapuis $[6,49]$, and $e$ is void ratio.

$d_{50}$, which corresponds to the sieve size that $50 \%$ of the particles by weight pass through, of the four cases are $0.06 \mathrm{~mm}, 0.2 \mathrm{~mm}, 0.1 \mathrm{~mm}$ and $0.07 \mathrm{~mm}$ respectively. According to Chinese soil classification standards (GBJ 145-90) [50], samples composed of PSD 1 and PSD 4 are silts, while samples composed of PSD 2 and 4 are sands. The results are shown in Fig. 11 with fitted parameters listed in Table 1. The air entry values are $4.0 \mathrm{kPa}, 3.23 \mathrm{kPa}, 4.76 \mathrm{kPa}$ and $3.45 \mathrm{kPa}$ respectively, close to that of Ottawa sand $2.2 \mathrm{kPa}$ [51]. Without considering physicalchemical processes and complicated microstructure, they seem to be a bit smaller than the air entry value of silt, for example, Barcelona silt $14.9 \mathrm{kPa}$ [44]. On the other hand, the fitted parameters $n$ of soil samples composed of PSD 2 and PSD 3 are smaller than those composed of PSD 1 and PSD 4 in Table 1, which shows that the SWCC of soil of well graded PSD is smoother than those of poorly graded PSD as also shown in Fig. 11. In accordance with experiment [6], Fig. 11 also exhibits that the water content in saturated soil of the poorly graded PSD is bigger than that of the well graded PSD if inter-particle angles are the same during sample generation.

Fig. 12 is the evolution diagram of permeability with suction. Soil samples composed of PSD 1 and PSD 4 exhibit larger permeability than the other two. With the same generation method, it is found that the sample produced from well graded PSD exhibits smaller void ratio,

Table 1

Fitted results of the four cases made of different PSDs by VG model.

\begin{tabular}{lllll}
\hline Item & PSD 1 & PSD 2 & PSD 3 & PSD 4 \\
\hline$\alpha\left(\mathrm{cm}^{-1}\right)$ & 0.025 & 0.031 & 0.021 & 0.029 \\
$n$ & 2.09 & 1.68 & 1.81 & 1.85 \\
$\mathrm{R}^{2}$ & 0.990 & 0.997 & 0.998 & 0.996 \\
\hline
\end{tabular}

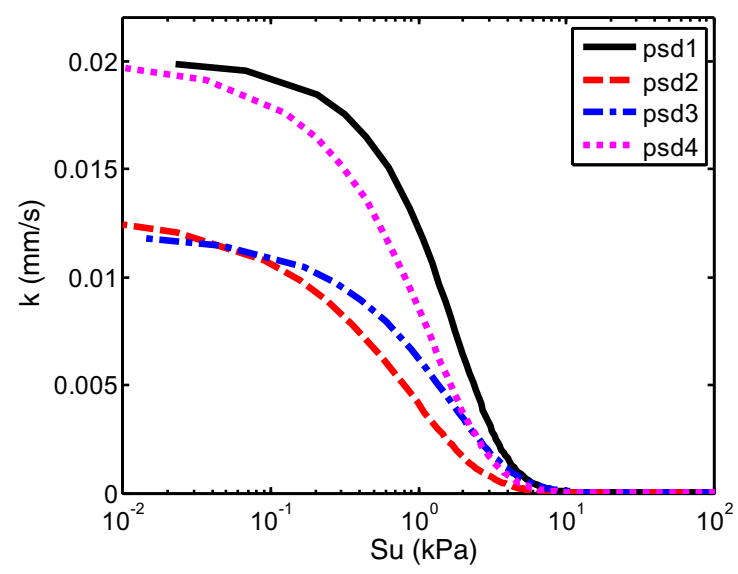

Fig. 12. Permeability versus suction of the four cases made of different PSDs.

which holds smaller permeability than that generated from poorly graded PSD.

\subsection{Influences of packing density}

To examine the influences of packing density on SWCC, four different inter-particle angles, $0.5^{\circ}, 10^{\circ}, 20^{\circ}$ and $30^{\circ}$ are assumed during the

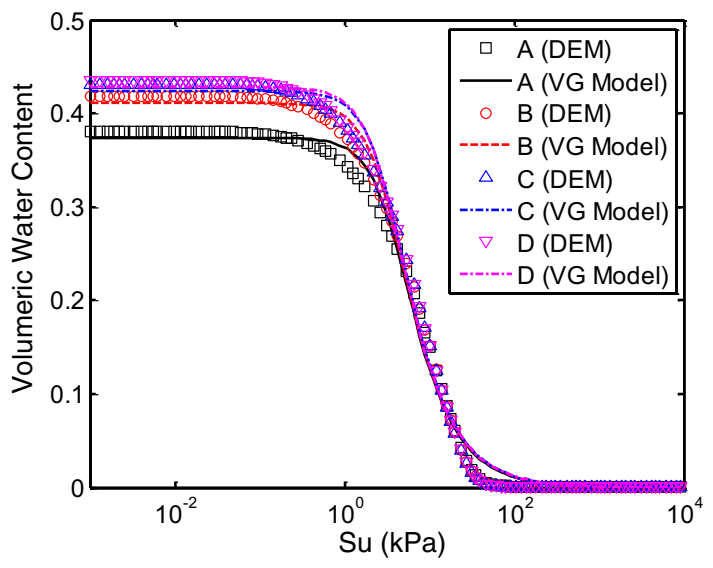

Fig. 13. SWCCs and fitted results by VG model of the four cases of different initial porosities. Porosities of A, B, C and D are $0.371,0.407,0.421$ and 0.430 , respectively.

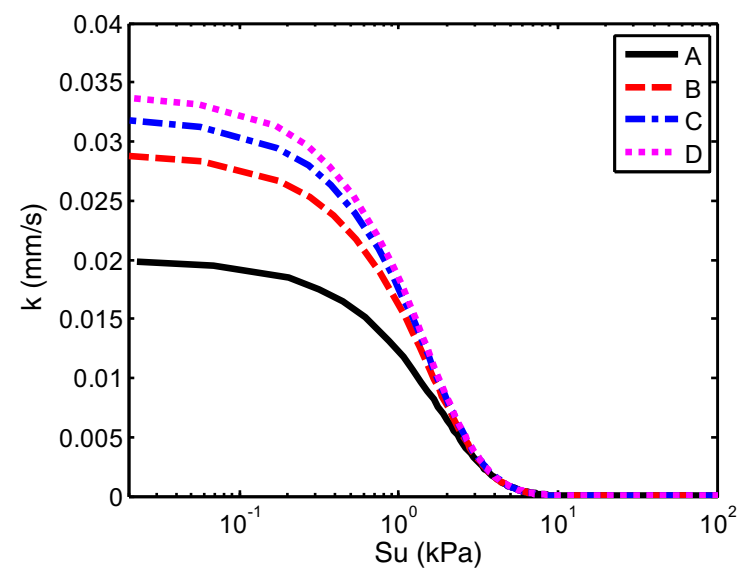

Fig. 14. Permeability predicted by VG model of four cases corresponding to different initial porosities. 


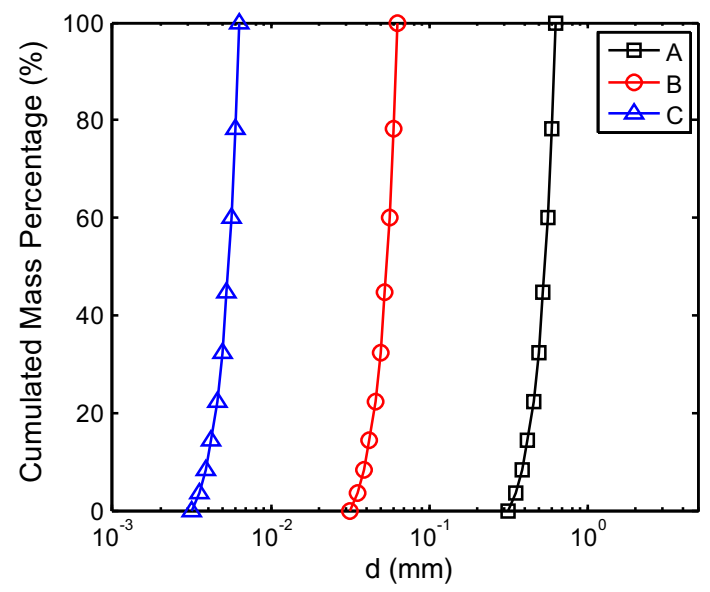

Fig. 15. PSDs of the three cases of different grain sizes, here $d$ is particle diameter, and $d_{50}$ which corresponds to the sieve sizes that $50 \%$ of the particles by weight pass through of the four samples are $0.5 \mathrm{~mm}, 0.05 \mathrm{~mm}, 0.005 \mathrm{~mm}$, respectively, and the coefficients of uniformity $\mathrm{Cu}\left(d_{60} / d_{10}\right)$ are all 1.4 for the three samples.

radius expansion process to generate samples with different initial porosities of $0.371,0.407,0.421$ and 0.430 , which are denoted as samples A, B ,C and D, respectively. Then suction controlled tests of SWCC were carried out with the required parameters simultaneously monitored. From Figs. 13 and 11, it is found that SWCC is more sensitive to the change of PSD than packing density. The water content in saturated state of denser sample is evidently less than that of looser sample, which is in accordance with Touchet silt [52] and 2\# silt of Huang' experiment [53].

Fig. 14 demonstrates the relationship between permeability and suction. Dense samples with small pore spaces exhibit small permeability.

\subsection{Influences of grain size}

Particle size plays an important role for SWCC of granular materials. To our knowledge, finer soil possesses larger water-holding capacity than coarser soil [7]. In order to reduce the influence of physical-chemical factors in clay particles, we restrict the size of particles in the range of sand and silt, the behavior of which is mainly governed by capillary effect. And then three samples with similar PSDs and $d_{50}$ of $0.5 \mathrm{~mm}$, $0.05 \mathrm{~mm}$ and $0.005 \mathrm{~mm}$ were generated, representing typical coarse sand, coarse silt and fine silt, respectively. Suction controlled tests

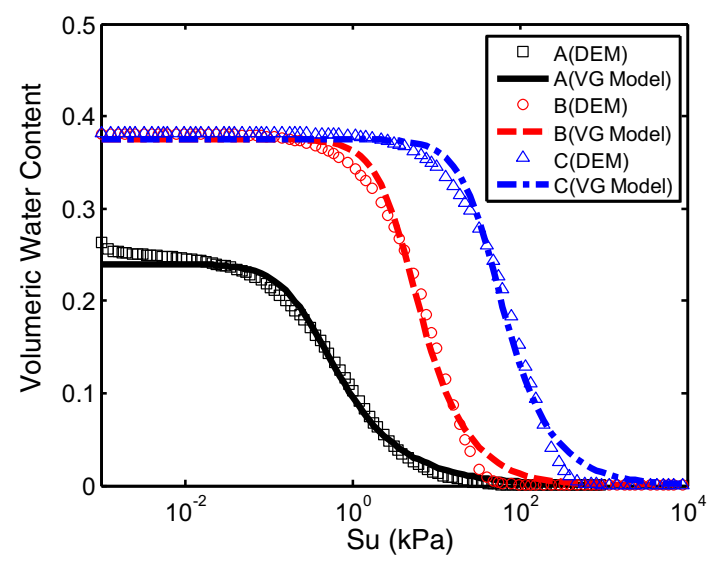

Fig. 16. SWCCs and fitted results by VG model of the three cases of different effective sizes. $d_{50}$ of A, B and C are $0.5 \mathrm{~mm}, 0.05 \mathrm{~mm}$ and $0.005 \mathrm{~mm}$ respectively.
Table 2

Fitted results of the three cases made of different grain size particles by VG model.

\begin{tabular}{llll}
\hline Item & A & B & C \\
\hline$\alpha\left(\mathrm{cm}^{-1}\right)$ & 0.345 & 0.026 & 0.003 \\
$n$ & 1.70 & 2.03 & 2.02 \\
$\mathrm{R}^{2}$ & 0.995 & 0.993 & 0.991 \\
\hline
\end{tabular}

were undertaken over the three samples with the desired parameters monitored. The PSDs of three samples can be found in Fig. 15. Then their SWCCs are shown in Fig. 16 showing that SWCCs of similar PSDs are similar. The fitting parameters via VG model are shown in Table 2.

From Table 2, it is calculated that the air entry values for sand, coarse silt and fine silt are $0.3 \mathrm{kPa}, 3.8 \mathrm{kPa}$ and $33.3 \mathrm{kPa}$, respectively. For simple cubic granular packing with the effective diameters, calculated via Eq. (11), the air entry values are $0.1 \mathrm{kPa}, 1.0 \mathrm{kPa}$ and $10.3 \mathrm{k}$, respectively. Air entry values of disperse and randomly packing granular materials are in the same order as the ideal cubic packing sample made of the same effective diameter particles. Lu [44] has collected properties of several kinds of soils including sand, silt, clay and mixtures of them, in which air entry of Ottawa fine sand is $2.2 \mathrm{kPa}$, that of Barcelona silt is $14.9 \mathrm{kPa}$. The air entry values of numerical results for both sand and silt is in the same order with typical soils. Although soil is modeled with spherical particles packing without considering any physicalchemical effect and complicated microstructure of pores, the fundamental trend of SWCC of sand and silt can be close to the experimental results, in particular, the air entry value is in the same magnitude of order as typical sand and silt.

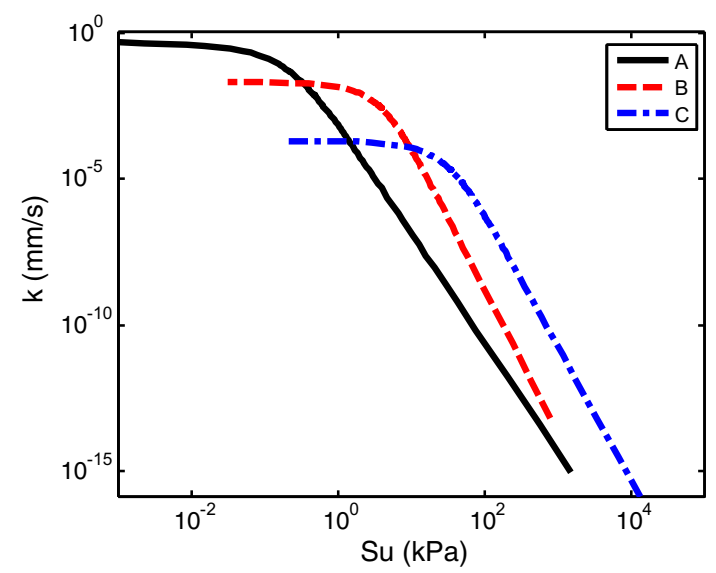

Fig. 17. Permeability predicted by VG model of three cases of different effective grain sizes. $d_{50}$ of A, B and C are $0.5 \mathrm{~mm}, 0.05 \mathrm{~mm}$ and $0.005 \mathrm{~mm}$ respectively.

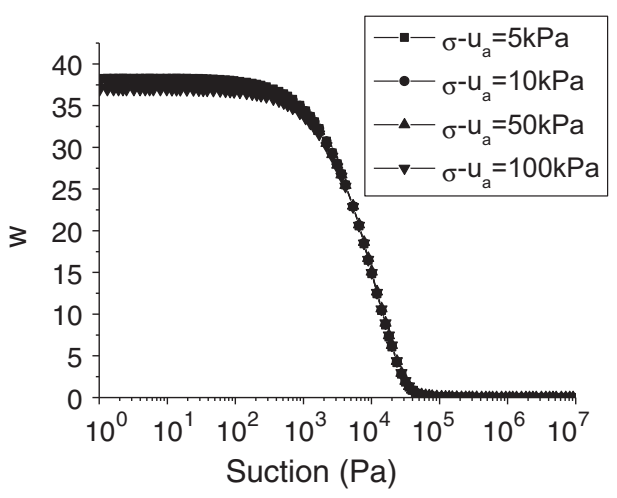

Fig. 18. SWCCs of granular materials under four different confining stresses, $5 \mathrm{kPa}, 10 \mathrm{kPa}$, $50 \mathrm{kPa}$ and $100 \mathrm{kPa}$, respectively. 


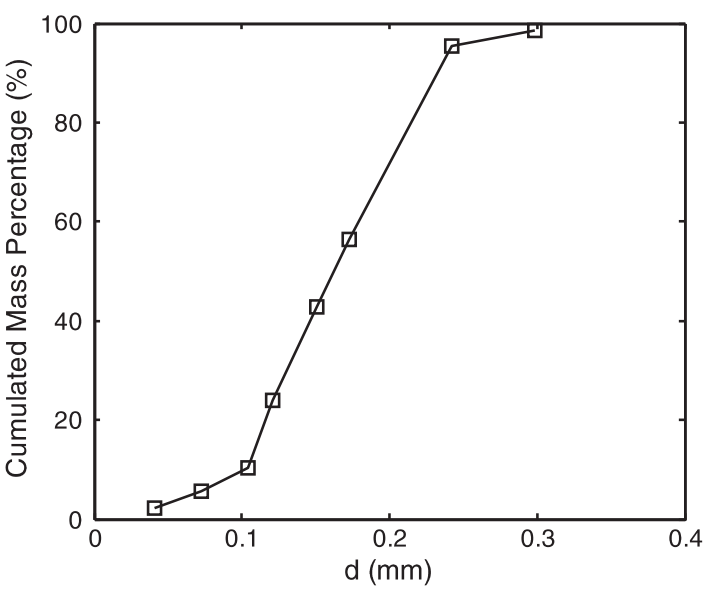

Fig. 19. PSD of the sandy soil with silt from Lu [7].

All of these results indicate that spherical packing model with liquid bridge model based on Young-Laplace theory and together with the proposed "Redistribution of Air Volume and Reduction of Liquid Bridge Force" approach is reasonable and promising for modeling fundamental behavior of unsaturated granular materials. It is also proved that holding water capacity of finer grain soil is better than coarser grain soil. From Fig. 17, the permeability curves of similar PSDs are also similar, and under the same suction. Under low suction, most of the pores are filled with water, and permeability is mainly determined by $S_{0}$ in Eq. (15), so fine grain soil with larger $S_{0}$ exhibits lower permeability as shown in the low suction region in Fig. 15. On the other hand, for high suction, fine soil may have better water-holding capacity than coarse soil, so permeability of fine soil is larger than coarse soil as shown in the large suction region as shown in Fig. 17.

\subsection{Influence of confining stress}

In order to address the influence of confining stress on SWCC, a granular sample is generated at confining stress $5 \mathrm{kPa}$, then consolidation is applied to the initial sample by moving the walls to achieve different confining stresses of $10 \mathrm{kPa}, 50 \mathrm{kPa}$ and $100 \mathrm{kPa}$. Then controlled suction tests were carried out with SWCCs given in Fig. 18. It is shown that confining stress plays very little role on SWCC, and also relative permeability. The circumstance also proves that granular materials made of particles are very much like porous media whose permeability is almost independent of stress. In contrast, the permeability of fracture rock heavily depends on stress exerted on the fracture.

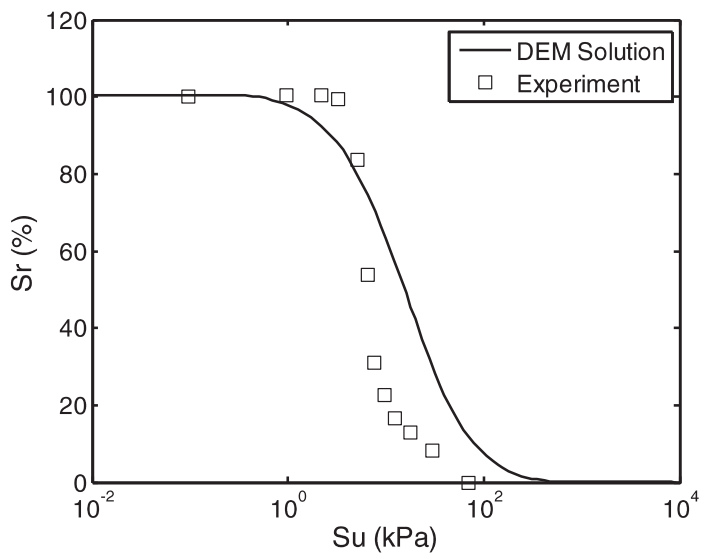

Fig. 20. SWCC predicted by the modified DEM and the experimental counterparts.

\section{A case study for sandy soil}

Now this modified DEM method is used to predict SWCC for a sandy soil with some silt which is taken from the experiment case from Lu [7]. Fig. 19 shows the PSD of the sandy soil, which is a narrow and poorly graded PSD, but rather suitable for DEM simulation. Fig. 20 is the prediction of SWCC by the modified DEM with 40,000 particles. The main trend of the prediction follows the experimental result. However, the DEM result seems to be a bit smoother than the experimental counterpart. This difference may be due to the inaccuracy of using sphere particles instead of angular particles.

\section{Conclusions}

To resolve the drawbacks that liquid bridge model based on YangLaplace theory can only be applied in pendular state of wet granular materials, a new approach called "Redistribution of Air Volume and Reduction of Liquid Bridge Force" is proposed. DEM incorporated with the new approach is capable of simulating behavior of granular materials in both funicular and capillary regimes. SWCC and SSCC of simple cubic granular packing and tetrahedral packing are obtained with very close agreement with the analytical solutions.

Typical SWCCs of sand and silt predicted by the modified DEM exhibit similar trend with soil experiments, in particular, the air entry value is very close to typical soil. The case study for the sandy soil shows that the modified DEM is able to predict SWCC of some real granular material. Combined with Mualem's theory and Kozeny-Carman equation, both SWCC and permeability are obtained, which can be applied to engineering, such as rainfall induced landslides and water transportation in vadose zone in agriculture engineering. The basic constitutive relationship and major parameters are provided for the unsaturated seepage field problems.

In conclusion, the liquid bridge model based on Yang-Laplace theory for spherical particle packing along with "Redistribution of Air Volume and Reduction of Liquid Bridge Force" approach is a promising micromechanical scheme to simulate behavior of unsaturated granular materials covering saturation from 0 to $100 \%$. It provides a simulation framework for hydro-mechanical coupling property study by couple particle level mechanics and pore scale capillary effect for granular materials. The future direction will be directed but not limited to the following aspects:

(1) Suction controlled numerical triaxial apparatus should be developed to consider mechanical and hydraulic behaviors of granular materials, especially the softening mechanism during seepage flow.

(2) More inter-particle based physical-chemical process should be developed, to extend the "qualitative and semi-quantitative" modeling stages to "semi-quantitative and quantitative" modeling stages for unsaturated granular material studies.

(3) Based on proposed modified DEM, numerical triaxial tests are recommended for application in the prediction of hydraulic and mechanical behaviors for typical unsaturated soil so that some of engineering problems in this regard such as rainfall induced landslides can be solved.

\section{Acknowledgments}

This work is financially supported under grants 11432015 and 10932012 by the National Natural Science Funds of China. The authors want to thank all the people on Yade Launchpad for helpful discussion on modeling unsaturated granular material. The first author appreciates helpful discussions with his colleagues B. Peng and Z. Zhang. 


\section{Appendix A. Supplementary data}

Supplementary data to this article can be found online at http://dx. doi.org/10.1016/j.powtec.2015.01.044.

\section{References}

[1] D.G. Fredlund, H. Rahardjo, Soil Mechanics for Unsaturated Soils, Wiley-interscience, 1993.

[2] N. Mitarai, F. Nori, Wet granular materials, Adv. Phys. 55 (1-2) (2006) 1-45.

[3] J.W. Godt, B. Sener-Kaya, N. Lu, R.L. Baum, Stability of infinite slopes under transient partially saturated seepage conditions, Water Resour. Res. 3 (May 2012) 48.

[4] G. Sorbino, M.V. Nicotera, Unsaturated soil mechanics in rainfall-induced flow landslides, Eng. Geol. 165 (2013) 105-132.

[5] Z. Fu, J. Li, Strength softening models of soil and its application in rainfall-induced landslide simulation, Theor. Appl. Mech. Lett. 3 (4) (2013) 042002.

[6] J.K. Mitchel, Fundamentals of Soil Behaviour, John Wiley \& Sons, New York, 1993.

[7] N. Lu, W.J. Likos, Unsaturated Soil Mechanics, J. Wiley, 2004.

[8] X. Li, Thermodynamics-based constitutive framework for unsaturated soils. 1: Theory, Geotechnique 57 (5) (2007) 411-422.

[9] D. Sheng, S. Sloan, A. Gens, A constitutive model for unsaturated soils: thermomechanical and computational aspects, Comput. Mech. 33 (6) (2004) 453-465.

[10] A. Gens, Soil-environment interactions in geotechnical engineering, Geotechnique 60 (1) (2010) 3-74.

[11] R.H. Brooks, A.T. Corey, Hydraulic properties of porous media, Hydrology Papers, Colorado State University, March 1964.

[12] M.T. Van Genuchten, A closed-form equation for predicting the hydraulic conductivity of unsaturated soils, Soil Sci. Soc. Am. J. 44 (5) (1980) 892-898.

[13] D. Fredlund, A. Xing, S. Huang, Predicting the permeability function for unsaturated soils using the soil-water characteristic curve, Can. Geotech. J. 31 (4) (1994) 533-546.

[14] Lalit M. Arya, Jack F. Paris, A physicoempirical model to predict the soil moisture characteristic from particle-size distribution and bulk density data, Soil Sci. Soc. Am. J. 45 (6) (1981) 1023-1030.

[15] R.T. Haverkamp, J.-Y. Parlange, Predicting the water-retention curve from particlesize distribution: 1. Sandy soils without organic matter1, Soil Sci. 142 (6) (1986) 325-339.

[16] M.H. Mohammadi, F. Meskini-Vishkaee, Predicting the film and lens water volume between soil particles using particle size distribution data, J. Hydrol. 475 (Dec 19 2012) 403-414.

[17] Y. Mualem, Hysteretical models for prediction of the hydraulic conductivity of unsaturated porous media, Water Resour. Res. 12 (6) (1976) 1248-1254.

[18] N. Burdine, Relative permeability calculations from pore size distribution data, J. Pet. Technol. 5 (3) (1953) 71-78.

[19] P.A. Cundall, O.D.L. Strack, A discrete numerical model for granular assemblies, Geotechnique 29 (1) (1979) 47-65.

[20] K. Iwashita, M. Oda, Rolling resistance at contacts in simulation of shear band development by DEM, J. Eng. Mech. 124 (3) (1998) 285-292.

[21] J.P. Plassiard, N. Belheine, F.V. Donze, A spherical discrete element model: calibration procedure and incremental response, Granul. Matter 11 (5) (Oct 2009) 293-306.

[22] M.J. Jiang, H.S. Yu, D. Harris, A novel discrete model for granular material incorporating rolling resistance, Comput. Geotech. 32 (5) (2005) 340-357.

[23] X. Wang, J. Li, Simulation of Triaxial Response of Granular Materials by Modified DEM. SCIENCE CHINA Physics, Mechanics \& Astronomy 57 (12) (2014) 2297-2308.

[24] J. Kozicki, F.V. Donze, YADE-OPEN DEM: an open-source software using a discrete element method to simulate granular material, Eng. Comput. 26 (7-8) (2009) 786-805.

[25] M. Yao, A. Anandarajah, Three-dimensional discrete element method of analysis of clays, J. Eng. Mech. ASCE 129 (6) (Jun 2003) 585-596.

[26] A. Anandarajah, Discrete element modeling of leaching-induced apparent overconsolidation in kaolinite, Soils Found. 43 (6) (Dec 2003) 1-12.
[27] M. Jiang, Z. Shen, C. Thornton, Microscopic contact model of lunar regolith for high efficiency discrete element analyses, Comput. Geotech. 54 (2013) 104-116.

[28] V. Richefeu, M.S. El Youssoufi, R. Peyroux, F. Radjaï, A model of capillary cohesion for numerical simulations of 3D polydisperse granular media, Int. J. Numer. Anal. Methods Geomech. 32 (11) (2008) 1365-1383.

[29] V. Richefeu, M.S.E. Youssoufi, F. Radjaï, Shear strength of unsaturated soils: experiments, DEM simulations, and micromechanical analysis, Theoretical and Numerical Unsaturated Soil Mechanics2007. 83-91.

[30] U. El Shamy, T. Gröger, Micromechanical aspects of the shear strength of wet granular soils, Int. J. Numer. Anal. Methods Geomech. 32 (14) (2008) 1763-1790.

[31] F. Soulié, M.S.E. Youssoufi, J.Y. Delenne, C. Saix, Effect of capillary and cemented bonds on the strength of unsaturated sands, Experimental Unsaturated Soil Mechanics2007. 185-193.

[32] M. Jiang, S. Leroueil, J. Konrad, Insight into shear strength functions of unsaturated granulates by DEM analyses, Comput. Geotech. 31 (6) (2004) 473-489.

[33] L. Scholtes, B. Chareyre, F. Nicot, F. Darve, Micromechanics of granular materials with capillary effects, Int. J. Eng. Sci. 47 (1) (Jan 2009) 64-75.

[34] L. Scholtes, B. Chareyre, F. Nicot, F. Darve, Discrete modelling of capillary mechanisms in multi-phase granular media, CMES Comput. Model. Eng. Sci. 52 (3) (Nov 2009) 297-318.

[35] L. Scholtes, P.Y. Hicher, F. Nicot, B. Chareyre, F. Darve, On the capillary stress tensor in wet granular materials, Int. J. Numer. Anal. Methods Geomech. 33 (10) (Jul 2009) 1289-1313.

[36] M.J. Jiang, H.S. Yu, D. Harris, Bond rolling resistance and its effect on yielding of bonded granulates by DEM analyses, Int. J. Numer. Anal. Methods Geomech. 30 (8) (Jul 2006) 723-761.

[37] N. Belheine, J.P. Plasslard, F.V. Donze, F. Darve, A. Seridi, Numerical simulation of drained triaxial test using 3D discrete element modeling, Comput. Geotech. 36 (1-2) (Jan-Mar 2009) 320-331.

[38] N. Cho, C.D. Martin, D.C. Sego, A clumped particle model for rock, Int. J. Rock Mech. Min. Sci. 44 (7) (Oct 2007) 997-1010.

[39] J. Duriez, F. Darve, F.V. Donze, A discrete modeling-based constitutive relation for infilled rock joints, Int. J. Rock Mech. Min. Sci. 48 (3) (2011) 458-468.

[40] V. Šmilauer, E. Catalano, B. Chareyre, S. Dorofeenko, J. Duriez, A. Gladky, et al., Yade Documentation, The Yade Project2010. (http://yade-demorg/doc/).

[41] V. Šmilauer, A. Gladky, J. Kozicki, C. Modenese, Stránský J. Yade, Using and programming, Yade Documentation2010.

[42] N. Lu, Is matric suction a stress variable? J. Geotech. Geoenviron. 134 (7) (2008) 899-905.

[43] N. Lu, W.J. Likos, Suction stress characteristic curve for unsaturated soil, J. Geotech. Geoenviron. 132 (2) (Feb 2006) 131-142.

[44] N. Lu, J.W. Godt, D.T. Wu, A closed-form equation for effective stress in unsaturated soil, Water Resour. Res, 46 (May 2010).

[45] Y.S. Song, W.K. Hwang, S.J. Jung, T.H. Kim, A comparative study of suction stress between sand and silt under unsaturated conditions, Eng. Geol. 124 (Jan 2012) 90-97.

[46] N. Lu, J. Godt, Infinite slope stability under steady unsaturated seepage conditions, Water Resour. Res. 44 (11) (Nov 2008).

[47] C. Voivret, F. Radjai, J.Y. Delenne, M. El Youssoufi, Space-filling properties of polydisperse granular media, Phys. Rev. E. 76 (2) (2007) 021301.

[48] M.T. Van Genuchten, F. Leij, S. Yates, The RETC Code for Quantifying the Hydraulic Functions of Unsaturated Soils, 1991.

[49] R.P. Chapuis, M. Aubertin, On the use of the Kozeny-Carman equation to predict the hydraulic conductivity of soils, Can. Geotech. J. 40 (3) (Jun 2003) 616-628.

[50] China MoWRotPsRo, Specification of Soil Test, China WaterPower Press, Beijing, 1999.

[51] T.-H. Kim, Moisture-induced Tensile Strength and Cohesion in Sand, University of Colorado, 2001.

[52] G.E. Laliberte, A.T. Corey, R. Brooks, Properties of Unsaturated Porous Media, Colorado State University Fort-Collins, Colorado, 1966.

[53] S. Huang, S. Barbour, D. Fredlund, Development and verification of a coefficient of permeability function for a deformable unsaturated soil, Can. Geotech. J. 35 (3) (1998) 411-425. 